\title{
Circulating Molecular Variants of Growth Hormone in Childhood
}

\author{
G. BAUMANN, R. J. WINTER, AND M. SHAW
}

Center for Endocrinology, Metabolism, and Nutrition, Departments of Medicine and Pediatrics, Northwestern University Medical School, Chicago, Illinois 60611

\begin{abstract}
Human growth hormone (hGH) is known to consist of several molecular forms. We examined the molecular nature of circulating hGH in 18 normal children and compared the resulting patterns to those previously obtained in adults. hGH secretion was stimulated with $\mathrm{L}$ dopa, the hormonal forms were extracted from plasma by immunoadsorbent chromatography, and their molecular nature was analyzed by polyacrylamide gel electrophoresis. Circulating monomeric hGH consisted of $73 \% \mathbf{h G H}_{22 \mathrm{~K}}$, $16 \% \mathrm{hGH}_{20 \mathrm{~K}}$, and $10 \%$ of an acidic $\mathrm{hGH}$ from $\left(\mathrm{N}_{\alpha}\right.$-acylated or deamidated hGH). These relative proportions are indistinguishable from those found in the plasma of adults. No age or sex differences in the circulating hGH pattern were found. We conclude that the types and proportions of hGH forms in the blood of normal children are the same as those previously established in adults. These data provide a framework against which children with postulated structurally abnormal ("bioinactive") hGH can be compared. (Pediatr Res 22: 21-22, 1987)
\end{abstract}

\section{Abbreviations}

hGH, human growth hormone

PAGE, polyacrylamide gel electrophoresis

SDS, sodium dodecyl sulfate

hGH consists of several distinct molecular forms $(1,2)$. Recent evidence has shown that in adult man, at least three monomeric species and several hGH oligomers circulate in blood (3-7). The three hGH monomers comprise the 22,000 dalton form $\left(\mathrm{hGH}_{22 \mathrm{~K}}\right)$, the 20,000 dalton variant $\left(\mathrm{hGH}_{20 \mathrm{~K}}\right)$, and an acidic form which has not been structurally elucidated. The latter could represent $\mathrm{N}_{t r}$-acylated (8), deamidated (9), cleaved $(10,11)$, or glycosylated hGH. Corresponding oligomeric aggregates up to the pentamer have also been identified in the circulation (7). The relative proportions of the various molecular forms have been found to be fairly constant and independent of the type of secretory stimulus (12). The precise physiological role of the various hGH forms remains to be elucidated.

To date, such data have only been obtained in adult subjects, primarily because of the large amount of plasma required for analysis. Since hGH serves its most conspicuous function in childhood, it is of interest to extend studies on the circulating $\mathrm{hGH}$ forms to the pediatric age group. The precise definition of the molecular nature of circulating $\mathrm{hGH}$ in normal children is of particular importance in view of the concept of an abnormal

Received December 2, 1986; accepted January 28, 1987

Address reprint requests to G. Baumann, M.D.. 303 East Chicago Avenue, Chicago, IL 60611

Supported by a McGaw Medical Center Interinstitutional Research Grant and by NIH Grants AM 10699 and RR 0537. "bioinactive hGH" as a basis for growth failure $(13,14)$. Recent improvements in the sensitivity of analytical techniques have made it possible to achieve that goal.

\section{MATERIALS AND METHODS}

Subjects. Eighteen prepubertal children, aged 6-13 yr, participated in the study. Eleven were boys and seven were girls. All underwent a standard L-dopa test $\left(500 \mathrm{mg} / \mathrm{m}^{2}\right)$ and blood was drawn at 30,60 , and 90 min after administration of the secretagogue. The tests were performed as part of the diagnostic procedures for short stature. All children had normal growth velocity. Ethical considerations prompted us to perform pharmacological testing and venipunctures only in children where a medical indication existed. Following full diagnostic work-up, all children were found to have normal endocrine function and no identifiable disease. The subsequent clinical course over a $2-y r$ period confirmed this assessment. All children had peak hGH responses exceeding $7 \mathrm{ng} / \mathrm{ml}$ (range $9.7-35.6 \mathrm{ng} / \mathrm{ml}$ ) after Ldopa. Blood samples obtained at the time of spontaneous elevation of hGH in two children were also included. The procedures had been approved by the Institutional Review Boards for Human Experimentation at both participating institutions.

Analysis. Plasma from one to three time points was pooled to yield a minimum quantity of hGH of $20 \mathrm{ng}$ (range 20-108 ng). $\mathrm{hGH}$ and all its variants were then extracted from plasma by immunoadsorbent chromatography as described in detail previously (3). The extracted hGH was analyzed for molecular variants by PAGE under nondenaturing conditions at $\mathrm{pH} 7.5$ in a discontinuous TES-acetate-chloride-Bistris buffer system. Experimental details of these procedures have been reported previously $(3,15)$. Gels were sliced into $1-\mathrm{mm}$ thick slices, slices were eluted, and eluates were assayed for $\mathrm{hGH}$ by radioimmunoassay. In all PAGE runs, known hGH forms were included as electrophoretic standards. Immunoreactive peaks in the slice eluates were classified with respect to their molecular nature i.e. which hGH form they represented, and then quantitated by peak integration as described previously (12). Comparison with analogous data in adult man, or between boys and girls, was made using the $t$ statistic.

\section{RESULTS}

A composite gel profile of plasma $\mathrm{hGH}$ from all children is shown in Figure 1. It is evident that $\mathrm{hGH}_{22 \mathrm{~K}}$ is the dominant molecular species. There is also evidence for the presence of $\mathrm{hGH}_{20 \mathrm{~K}}$ and a faster-migrating form (acidic hGH). The latter may represent $\mathrm{N}_{c x}$-acylated or deamidated $\mathrm{hGH}$. The profile is very similar to those previously reported for adult subjects $(4,5$. 12). No new or previously unrecognized hGH forms were seen. Quantitation of the $3 \mathrm{hGH}$ forms in individual subjects yielded data tabulated in Table 1. There was no significant difference between the hGH forms circulating in boys or girls. Data from all children were therefore pooled. The relative proportions of 


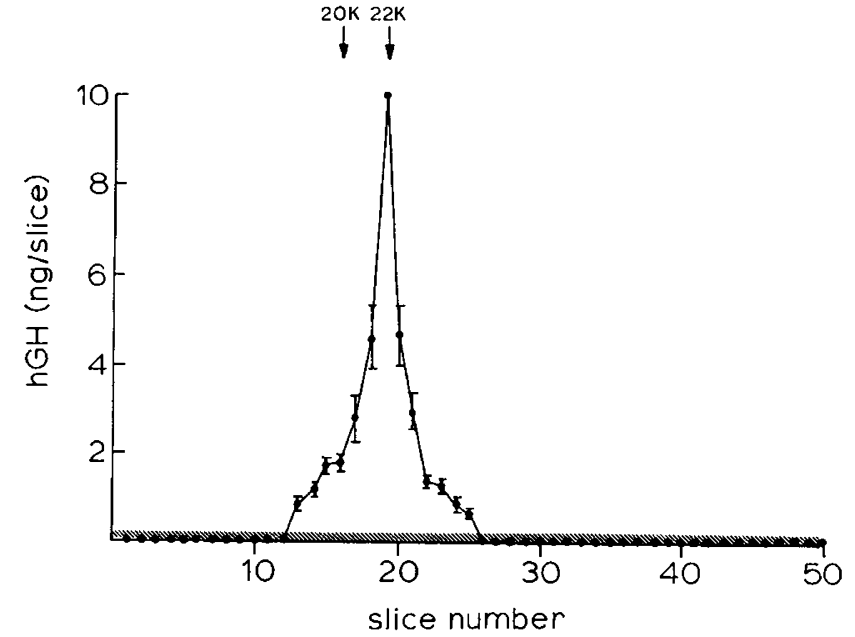

Fig. 1. Composite PAGE profile of plasma hGH in 18 children. Plasma extracts were run in native PAGE at pH 7.5, gels sliced into 1$\mathrm{mm}$ slices, and slice eluates assayed for hGH. Individual profiles were normalized by equalizing the $\mathrm{hGH}_{22 \mathrm{~K}}$ peak height to $10 \mathrm{ng}$ and proportionate adjustment of the entire profile in order to permit statistical treatment (3). $20 \mathrm{~K}$ and $22 \mathrm{~K}$ denote the positions of $\mathrm{hGH}_{20 \mathrm{~K}}$ and $\mathrm{hGH}_{22 \mathrm{~K}}$, respectively, in the gel. Bars denote SEM and the hatched area denotes the undetectable range.

Table 1. Proportions of molecular forms of hGH in plasma (mean $\pm S E M$ and range)

\begin{tabular}{cccc}
\hline & $\begin{array}{c}\mathrm{hGH}_{22 \mathrm{~K}} \\
(\%)\end{array}$ & $\begin{array}{c}\mathrm{hGH}_{20 \mathrm{~K}} \\
(\%)\end{array}$ & $\begin{array}{c}\text { Acidic } \mathrm{hGH} \\
(\%)\end{array}$ \\
\hline Adults & $77.0 \pm 1.1$ & $\begin{array}{c}15.8 \pm 1.0 \\
(8-23)\end{array}$ & $\begin{array}{c}9.1 \pm 0.9 \\
(3-20)\end{array}$ \\
$\begin{array}{c}\text { age 21-47 yr } \\
(n=22)\end{array}$ & $(68-88)^{*}$ & $(8)$ & \\
Children & & & \\
age 6-13 yr & $(60-86)$ & $(8-30)$ & $(6-15)$ \\
$(n=18)$ & $\mathrm{NS}$ & $\mathrm{NS}$ & $p=0.08$ \\
\hline
\end{tabular}

* Numbers in parentheses are ranges.

the three plasma hGH forms in children were not significantly different from those in adults (Table 1), although acidic hGH was marginally more abundant in the children (Table 1).

\section{DISCUSSION}

The present study extends our previous observations on the molecular forms of hGH in blood to include children. The data show that the same three monomeric forms of hGH that circulate in adult man are present in children of various ages. Moreover, the relative proportions of these hGH forms are very similar in children and adults. We observed no sex difference or changes in the proportions as a function of age. It thus appears that the mixture of circulating hGH variants is relatively constant under a large variety of circumstances.

The limited amount of plasma available for study in those pediatric samples precluded analysis in all three electrophoretic systems that we have employed previously (i.e. native PAGE, SDS-PAGE, and isoelectric focusing). However, extensive expe- rience with all three systems has convinced us that native PAGE at $\mathrm{pH} 7.5$ provides the best resolution of hGH variants. The use of that system was therefore judged sufficient for the purposes of the present study, as previously discussed for adult plasma (12).

Further application of the techniques developed for examining circulating hGH forms to disorders with abnormal growth may help elucidate their nature. In this regard, it will be particularly interesting to determine whether short children with normal immunoassayable and presumed bioinactive $\mathrm{hGH}(13,14,16)$ have aberrant molecular hGH forms as the basis of their short stature.

In summary, we find that the hGH forms circulating in children of various ages are qualitatively and quantitatively the same as in adults. The extensive data collected in the latter are therefore representative for the pediatric population. There appears to be no additional hGH form(s) expressed during childhood.

Acknowledgments. The authors thank Ms. Helen D. Roque for help with the preparation of the manuscript. Presented at the Annual Meeting of the Central Society for Clinical Research, Chicago, October 1986 and reported in abstract form (Clin Res 1986;34:949A).

\section{REFERENCES}

1. Lewis UJ, Singh RNP, Tutweiler GF, Sigel MB, VanderLaan EF, VanderLaan WP 1980 Human growth hormone: a complex of proteins. Recent Prog Horm Res 36:477-508

2. Chawla RK, Parks JS, Rudman D 1983 Structural variants of human growth hormone: biochemical, genetic and clinical aspects. Ann Rev Med 34:519547

3. Baumann G, MacCart JC, Amburn K 1983 The molecular nature of circulating growth hormone in normal and acromegalic man: evidence for a principal and minor monomeric forms. J Clin Endocrinol Metab 56:946-952

4. Stolar MW, Baumann G, Vance ML, Thorner MO 1984 Circulating growth hormone forms after stimulation of pituitary secretion with growth hormonereleasing factor in man. J Clin Endocrinol Metab 59:235-239

5. Baumann G, Stolar MW, Amburn K 1985 Molecular forms of circulating growth hormone during spontaneous secretory episodes and in the basal state. J Clin Endocrinol Metab 60:1216-1220

6. Markoff E, Lee DW, Culler FL, Jones KL, Lewis UJ 1986 Release of the 22,000 and the 20,000 -dalton variants of growth hormone in vivo and in vitro by human anterior pituitary cells. J Clin Endocrinol Metab 62:664669

7. Stolar MW, Amburn K, Baumann G 1984 Plasma "big" and "big-big" growth hormone $(\mathrm{GH})$ in man: an oligomeric series composed of structurally diverse GH monomers. J Clin Endocrinol Metab 59:212-218

8. Lewis UJ, Singh RNP, Bonewald LF, Lewis LJ, VanderLaan WP 1979 Human growth hormone: additional members of the complex. Endocrinology 104:1256-1265

9. Lewis UJ, Singh RNP, Bonewald LF, Seavey BK 1981 Altered proteolytic cleavage of human growth hormone as a result of deamidation. J Biol Chem 256:11645-11650

10. Yadley RA, Chrambach A 1973 Isohormones of human growth hormone. II. Plasmin-catalyzed transformation and increase in prolactin biological activity. Endocrinology 93:848-865

11. Singh RNP, Seavey BI, Lindsey TT, Lewis UJ 1974 Modified forms of human growth hormone with increased biological activities. Endocrinology 94:883891

12. Baumann G, Stolar MW 1986 Molecular forms of human growth hormone secreted in vivo: Nonspecificity of secretory stimuli. J Clin Endocrinol Metab 62:789-790

13. Kowarski AA, Schneider J, Ben-Galim R, Weldon VV, Daughaday WH 1978 Growth failure with normal serum RIA-GH and low somatomedin activity: somatomedin restoration and growth acceleration after exogenous $\mathrm{GH}$. J Clin Endocrinol Metab 47:461-464

14. Frazer T, Gavin JR, Daughaday WH, Hillman RE, Weldon VV 1982 Growth hormone-dependent growth failure. J Pediatr 101:12-15

15. Baumann G, MacCart JG 1982 Growth hormone production by human pituitary glands in organ culture: evidence for predominant secretion of the single-chain 22,000 dalton form (isohormone B). J Clin Endocrinol Metab 55:611-618

16. Schaff-Blass E, Burstein S, Rosenfield RL 1984 Advances in diagnosis and treatment of short stature, with special reference to the role of growth hormone. J Pediatr 104:801-813 